\title{
Protonation sites and hydrogen bonding in mono-hydrobromide salts of two N,4-diheteroaryl 2-aminothiazoles
}

\author{
Denise Böck ${ }^{1}$ (D) - Andreas Beuchel ${ }^{1} \cdot$ Richard Goddard $^{2}$ (D) $\cdot$ Adrian Richter $^{1}$ (D) $\cdot$ Peter Imming $^{1}$ (D) • \\ Rüdiger W. Seidel ${ }^{1}$
}

Received: 13 November 2020 / Accepted: 11 January 2021 / Published online: 19 February 2021

(C) The Author(s) 2021

\begin{abstract}
The synthesis and structural characterization of $N$-(6-methoxypyridin-3-yl)-4-(pyridin-2-yl)thiazol-2-amine mono-hydrobromide monohydrate (3) and $N$-(6-methoxypyridin-3-yl)-4-(pyrazin-2-yl)thiazol-2-amine mono-hydrobromide 0.35 methanol solvate (4) are reported. The crystal structures of $\mathbf{3}$ (monoclinic, space group $P 2_{1} / n, Z=4$ ) and $\mathbf{4}$ (monoclinic, space group, $C 2 / c, Z=8$ ) feature $N, 4$-diheteroaryl 2-aminothiazoles showing similar molecular conformations but different sites of protonation and thus distinctly different intermolecular hydrogen bonding patterns. In $\mathbf{3}, \mathrm{N}_{\text {amine }}-\mathrm{H}^{\cdots} \mathrm{Br}^{-}, \mathrm{N}^{+}$pyridine $-\mathrm{H}^{\cdots} \mathrm{O}_{\text {water }}$, and $\mathrm{O}_{\text {water }}-\mathrm{H}^{\cdots} \mathrm{Br}^{-}$ hydrogen bonds link protonated $N$-(6-methoxypyridin-3-yl)-4-(pyridin-2-yl)thiazol-2-amine and water molecules and bromide anions into a three-dimensional hydrogen-bonded network, whereas intermolecular $\mathrm{N}^{+}$methoxypyridine $-\mathrm{H}^{\cdots} \mathrm{N}_{\text {pyrazine }}$ hydrogen bonds result in hydrogen-bonded zigzag chains of protonated $N$-(6-methoxypyridin-3-yl)-4-(pyrazin-2-yl)thiazol-2-amine molecules in 4.
\end{abstract}

Keywords 2-Aminothiazoles $\cdot$ Hydrobromides $\cdot$ Hantzsch reaction $\cdot$ Hydrogen bonding $\cdot$ Crystal structure $\cdot$ DFT calculation

\section{Introduction}

The 2-aminothiazole unit is a synthetically versatile building block, which has been widely used in medicinal chemistry. A number of active pharmaceutical ingredients containing a 2aminothiazole moiety with different pharmacological properties are on the market. They include, for example, the thirdgeneration cephalosporin anti-infective cefdinir, the $\beta_{3}$ adrenergic agonist mirabegron, the tyrosine kinase inhibitor dasatinib, and the recently approved phosphatidylinositol-3kinase (PI3K) inhibitor alpelisib. Antiproliferative, antidiabetic, antihypertensive, and anti-inflammatory properties as well as antiviral, antitubercular, antifungal, antileishmanial, and

Dedicated to Dr. Dietrich Seidel on the occasion of his 65 th birthday

Rüdiger W. Seidel

ruediger.seidel@pharmazie.uni-halle.de

1 Institut für Pharmazie, Martin-Luther-Universität Halle-Wittenberg, Wolfgang-Langenbeck-Str. 4, 06120 Halle (Saale), Germany

2 Max-Planck-Institut für Kohlenforschung, Kaiser-Wilhelm-Platz 1, 45470 Mülheim an der Ruhr, Germany antiprion activities of 2-aminothiazoles have been reported [1].

Antileishmanial properties of N,4-diaryl substituted 2aminothiazoles have been studied based on a hit in a screening of 200,000 compounds [2], and growth inhibition of other microorganisms including plasmodia [3] and mycobacteria [4] by this compound class has also been described. A series of $N, 4-$ diaryl 2-aminothiazoles with activity against Mycobacterium tuberculosis were subject of a structure-activity relationship (SAR) study reported by Meissner et al. [5]. Makam and Kannan evaluated N,4-diaryl substituted 2-aminothiazoles for inhibitory potential against $M$. tuberculosis, $\mathrm{H}_{37} \mathrm{Rv}$, and reported minimum inhibitory concentration (MIC) values of 6.25 $12.50 \mu \mathrm{M}[6]$. In view of these results, $N$,4-diheteroaryl substituted 2-aminothiazoles attracted our interest in the course of our studies on new antimycobacterial agents. Recently, we have explored the structural chemistry of freebase $N, 4$-diheteroaryl 2aminothiazoles with a 4-methylpyridin-2-yl group bound to the amino group at the 2-position of the thiazole core [7, 8].

Herein, we report the synthesis and structural characterization of two N,4-diheteroaryl 2-aminothiazole hydrobromides. Bromide is among the anions that are currently available for salt formation of active pharmaceutical ingredients [9], and a number of hydrobromide drugs, for example, the antitussive 
dextromethorphan hydrobromide, are widely used. To the best of our knowledge and based on the search of the Cambridge Structural Database (CSD) [10] via WebCSD in October 2020 [11], hydrobromide salts of $N, 4$-diaryl 2-aminothiazoles have not been structurally characterized so far. The structure of a related 4-phenyl-2-(2-phenylhydrazinyl)thiazol-3-ium bromide was, however, reported very recently [12]. Structural insight into molecular conformations, preferred sites of protonation, and hydrogen bonding patterns in pharmaceutical salt forms is important for drug design and formulation development.

\section{Experimental section}

\section{General}

Starting materials were purchased from Sigma-Aldrich and used as received. Solvents were of analytical grade. The synthesis of 2-bromo-1-(pyridin-2-yl)ethanone hydrobromide was published by others [13].

\section{Physical methods}

Melting points (uncorrected) were determined on a Boëtius hot-stage microscope (VEB Kombinat NAGEMA, Dresden, GDR). NMR spectra were recorded at room temperature on an Agilent Technologies VNMRS 400 and a Varian INOVA 500 NMR spectrometer. The residual solvent signal of DMSO- $d_{6}$ $\left(\delta_{\mathrm{H}}=2.50 \mathrm{ppm}\right)$ was used to reference the spectra ( $\mathrm{s}=$ singlet, bs = broad singlet, $\mathrm{d}=$ doublet, $\mathrm{dd}=$ doublet of doublets, $\mathrm{td}=$ triplet of doublets). APCI mass spectrometry was carried out on an Advion Expression compact mass spectrometer. Highresolution ESI mass spectra were measured on a Bruker Daltonics Apex III FT-ICR mass spectrometer.

\section{Synthesis and crystallization}

$\mathrm{N}$-((6-Methoxypyridin-3-yl)carbamothioyl)benzamide (1) [14] $2.90 \mathrm{~g}$ (23.4 mmol) of 2-methoxy-5-aminopyridine were dissolved in $70 \mathrm{~mL}$ of acetone and benzoyl isothiocyanate (3.3 $\mathrm{mL}, 24.5 \mathrm{mmol}$ ) was added dropwise with stirring. The reaction mixture was warmed to $40{ }^{\circ} \mathrm{C}$ for $10 \mathrm{~min}$, before the solvent was removed under reduced pressure. The crude product was recrystallized from acetone. Yield $4.44 \mathrm{~g}$ (15.5 mmol, $66 \%$ ). ${ }^{1} \mathrm{H}$ NMR (400 MHz, DMSO- $\left.d_{6}\right) \delta=12.30(\mathrm{~s}, 1 \mathrm{H})$, $11.66(\mathrm{~s}, 1 \mathrm{H}), 8.28$ (d, $J=2.7 \mathrm{~Hz}, 1 \mathrm{H}), 7.98(\mathrm{~m}, 2 \mathrm{H}), 7.93$ (dd, $J=8.8,2.7 \mathrm{~Hz}, 1 \mathrm{H}), 7.74-7.62(\mathrm{~m}, 1 \mathrm{H}), 7.55(\mathrm{~m}, 2 \mathrm{H})$, $6.88(\mathrm{~d}, J=8.8 \mathrm{~Hz}, 1 \mathrm{H}), 3.87$ (s, 3H) ppm; MS (APCI): $\mathrm{m} / z$ $[\mathrm{M}+\mathrm{H}]^{+}$calcd. for $\mathrm{C}_{14} \mathrm{H}_{14} \mathrm{~N}_{3} \mathrm{O}_{2} \mathrm{~S}^{+}$: 288; found 288 .

1-(6-Methoxypyridin-3-yl)thiourea (2) [14, 15] Compound 1 (4.44 g, $15.5 \mathrm{mmol}$ ) was suspended in $15 \mathrm{~mL}$ of methanol and $1.2 \mathrm{~mL}$ of $40 \%$ aqueous $\mathrm{NaOH}$ (17.2 mmol) was added. The solution turned clear and was heated to reflux for $1 \mathrm{~h}$. Subsequently, the solvent was removed under reduced pressure. The product was washed with water and dried in a vacuum desiccator over $\mathrm{P}_{2} \mathrm{O}_{5}$. Yield: $1.61 \mathrm{~g}(8.8 \mathrm{mmol}, 57 \%) .{ }^{1} \mathrm{H}$ NMR (400 MHz, DMSO-d $\left.d_{6}\right) \delta=9.50$ (bs, 1H), 8.05 (d, $J=$ $2.7 \mathrm{~Hz}, 1 \mathrm{H}), 7.70$ (dd, $J=8.8,2.7 \mathrm{~Hz}, 1 \mathrm{H}), 7.49$ (bs, 2H), 6.79 (d, $J=8.8 \mathrm{~Hz}, 1 \mathrm{H}), 3.83$ (s, 3H) ppm; MS (APCI): $m / z[\mathrm{M}+$ $\mathrm{H}]^{+}$calcd. for $\mathrm{C}_{7} \mathrm{H}_{10} \mathrm{~N}_{3} \mathrm{OS}^{+}$: 184; found: 184 .

N-(6-methoxypyridin-3-yl)-4-(pyridin-2-yl)thiazol-2-amine mono-hydrobromide monohydrate (3) 2-Bromo-1-(pyridine2-yl)ethanone hydrobromide $(696 \mathrm{mg}, 2.48 \mathrm{mmol})$ and $418 \mathrm{mg}$ ( $2.28 \mathrm{mmol})$ of 2 were dissolved in $20 \mathrm{~mL}$ of ethanol, and triethylamine $(0.1 \mathrm{~mL})$ was added. The reaction mixture was heated to reflux for $2 \mathrm{~h}$ and subsequently the solvent was removed under reduced pressure. The crude product was recrystallized from methanol. Yield $550 \mathrm{mg}$ (1.44 mmol, 63\%); m.p. $152-154{ }^{\circ} \mathrm{C} .{ }^{1} \mathrm{H}$ NMR (500 MHz, DMSO- $\left.d_{6}\right) \delta=10.59$ (s, 1H), $8.76(\mathrm{dd}, J=2.9,0.7 \mathrm{~Hz}, 1 \mathrm{H}), 8.75(\mathrm{dt}, J=5.6 \mathrm{~Hz}$, $1.2 \mathrm{~Hz}, 1 \mathrm{H}), 8.50-8.43(\mathrm{~m}, 2 \mathrm{H}), 8.14(\mathrm{~s}, 1 \mathrm{H}), 8.08$ (dd, $J=$ $8.8,2.9 \mathrm{~Hz}, 1 \mathrm{H}), 7.81(\mathrm{td}, J=5.6 \mathrm{~Hz}, 1 \mathrm{H}), 6.87$ (dd, $J=8.8$, $0.7 \mathrm{~Hz}, 1 \mathrm{H}), 3.85$ (s, 3H) ppm; HRMS (ESI): $\mathrm{m} / z[\mathrm{M}+\mathrm{H}]^{+}$ calcd. for $\mathrm{C}_{14} \mathrm{H}_{13} \mathrm{~N}_{4} \mathrm{OS}^{+} 285.0805$; found: 285.0800 .

N-(6-Methoxypyridin-3-yl)-4-(pyrazin-2-yl)thiazol-2-amine mono-hydrobromide 0.35 methanol solvate (4) Compound 4 was prepared in analogy to 3 from $2(453 \mathrm{mg}, 2.47 \mathrm{mmol})$ and 2-bromo-1-(pyrazine-2-yl) ethanone hydrobromide [16] (note that the compound is not denoted as hydrobromide therein), which was synthesized from acetylpyrazine $(305 \mathrm{mg}$, $2.50 \mathrm{mmol}$ ) using 2-pyrrolidone hydrotribromide (1.36 g, $2.74 \mathrm{mmol})$ as reagent and used in situ without purification. Yield (based on 2): $344 \mathrm{mg}$ (0.91 mmol, 37\%); m.p. 195 $197{ }^{\circ} \mathrm{C} .{ }^{1} \mathrm{H}$ NMR $\left(500 \mathrm{MHz}, \mathrm{DMSO}-d_{6}\right) \delta=10.49(\mathrm{~s}, 1 \mathrm{H})$, $9.18(\mathrm{~d}, J=1.5 \mathrm{~Hz}, 1 \mathrm{H}), 8.65$ (dd, $J=2.6,1.5 \mathrm{~Hz}, 1 \mathrm{H}), 8.63$ $(\mathrm{d}, J=2.8 \mathrm{~Hz}, 1 \mathrm{H}), 8.58$ (d, $J=2.5 \mathrm{~Hz}, 1 \mathrm{H}), 8.19$ (dd, $J=9.0$, $2.8 \mathrm{~Hz}, 1 \mathrm{H}), 7.68(\mathrm{~s}, 1 \mathrm{H}), 6.97$ (d, J=9.0 Hz, 1H), 3.88 (s, $3 \mathrm{H}), 3.16$ (s, solvate methanol) ppm; HRMS (ESI): $m / z[\mathrm{M}+$ $\mathrm{H}]^{+}$calcd. for $\mathrm{C}_{13} \mathrm{H}_{12} \mathrm{~N}_{4} \mathrm{OS}^{+} 286.0758$; found: 286.0753 .

\section{X-ray crystallography}

The X-ray intensity data for $\mathbf{3}$ were measured on a Bruker AXS Apex II diffractometer and those for $\mathbf{4}$ on an EnrafNonius KappaCCD diffractometer, both equipped with a FR591 rotating anode radiation source. Data reductions were performed using the SAINT software [17] for 3 and EvalCCD [18] for 4. In both cases, face-indexed absorption corrections were carried out using SADABS [19]. The crystal structures were solved with SHELXT-2018/1 [20] and refined with SHELXL-2018/3 [21]. The methanol molecule of crystallization in $\mathbf{4}$ is disordered about a crystallographic twofold 
Table 1 Crystal data and refinement details for $\mathbf{3}$ and $\mathbf{4}$

\begin{tabular}{|c|c|c|}
\hline & 3 & 4 \\
\hline Empirical formula & $\mathrm{C}_{14} \mathrm{H}_{15} \mathrm{BrN}_{4} \mathrm{O}_{2} \mathrm{~S}$ & $\mathrm{C}_{13.35} \mathrm{H}_{13.41} \mathrm{BrN}_{5} \mathrm{O}_{1.35} \mathrm{~S}$ \\
\hline$M_{\mathrm{r}}$ & 383.27 & 377.50 \\
\hline$T(\mathrm{~K})$ & $100(2)$ & $100(2)$ \\
\hline$\lambda(\AA)$ & 1.54178 & 0.71073 \\
\hline Crystal system & Monoclinic & Monoclinic \\
\hline Space group & $P 2_{1} / n$ & $C 2 / c$ \\
\hline$a(\AA)$ & $9.6904(4)$ & $17.4497(4)$ \\
\hline$b(\AA)$ & $17.6873(8)$ & $12.2030(5)$ \\
\hline$c(\AA)$ & $9.9215(4)$ & $15.3912(8)$ \\
\hline$\beta\left({ }^{\circ}\right)$ & $117.286(2)$ & $116.998(4)$ \\
\hline$V\left(\AA^{3}\right)$ & $1511.30(11)$ & $2920.2(2)$ \\
\hline$Z$ & 4 & 8 \\
\hline$\rho_{\text {calc }}\left(\mathrm{g} \mathrm{cm}^{-3}\right)$ & 1.684 & 1.717 \\
\hline$\mu\left(\mathrm{mm}^{-1}\right)$ & 5.118 & 2.968 \\
\hline$F(000)$ & 776 & 1523 \\
\hline Crystal size (mm) & $0.152 \times 0.101 \times 0.080$ & $0.110 \times 0.090 \times 0.050$ \\
\hline$\theta$ range $\left(^{\circ}\right)$ & $5.00-72.28$ & $2.91-33.18$ \\
\hline Reflections collected/unique & $56,808 / 2956$ & $36,295 / 5581$ \\
\hline$R_{\text {int }}$ & 0.0611 & 0.0804 \\
\hline Observed reflections $[I>2 \sigma(I)]$ & 2670 & 3747 \\
\hline Data/restraints/parameters & $2956 / 4 / 212$ & $5581 / 2 / 206$ \\
\hline Goodness-of-fit on $F^{2}$ & 1.168 & 1.040 \\
\hline$R 1[I>2 \sigma(I)]$ & 0.0322 & 0.0517 \\
\hline$w R 2$ (all data) & 0.0855 & 0.1136 \\
\hline$\Delta \rho_{\max }, \Delta \rho_{\min }\left(\mathrm{e}^{-3}\right)$ & $0.62,-1.19$ & $1.90,-2.01$ \\
\hline
\end{tabular}

rotation axis, and the occupancy was refined freely to yield $0.70(1)$, using isotropic displacement parameters for the carbon and oxygen atoms. Carbon-bound hydrogen atoms were placed in geometrically calculated positions with $\mathrm{C}_{\text {aromatic }}-$ $\mathrm{H}=0.95 \AA$ and $\mathrm{C}_{\text {methyl }}-\mathrm{H}=0.98 \AA$ and refined with the appropriate riding model. Methyl groups (apart from methanol) were allowed to rotate to match the underlying electron density maxima. Hydrogen atoms attached to nitrogen were localized in difference electron density maps and refined with the N-H bond lengths restrained to a target value of 0.88(2) $\AA$. $U_{\text {iso }}(\mathrm{H})=1.2 U_{\text {eq }}(\mathrm{C}, \mathrm{N}, \mathrm{O})$ (1.5 for methyl groups) was applied for all hydrogen atoms. We note that the highest difference electron density peak of $1.90 \mathrm{e}^{-3}$ in 4 is located $0.65 \AA$ from Br1. Crystal data and refinement details for 3 and $\mathbf{4}$ are summarized in Table 1. Structure pictures were generated with Diamond [22].

\section{Computational methods}

DFT calculations were undertaken using the program ORCA (version 4.2) [23] with a B3LYP hybrid functional (20\% HF exchange) [24, 25] using a def2-TZVPP basis set [26].<smiles>[X]=CO[Na]</smiles><smiles>COc1ccc(Nc2nc(-c3cnccn3)cs2)cn1</smiles>

Scheme 1 Synthesis of N,4-diheteroaryl 2-aminothiazole hydrobromides $\mathbf{3}$ and $\mathbf{4}$ from $\mathbf{2}$ and the respective $\alpha$-bromoketone hydrobromide. Solvent molecules of crystallization are not included. 
Fig. 1 Asymmetric units of $\mathbf{3}$ (top) and $\mathbf{4}$ (bottom).

Displacement ellipsoids are drawn at the $50 \%$ probability level. Hydrogen atoms are shown by small spheres of arbitrary radius. $\mathrm{N}_{\text {amine }}-\mathrm{H}^{\cdots} \mathrm{Br}^{-}$and $\mathrm{N}_{\text {pyridine }}^{+}-\mathrm{H}^{+} \mathrm{O}_{\text {water }}$ hydrogen bonds are represented by dashed lines
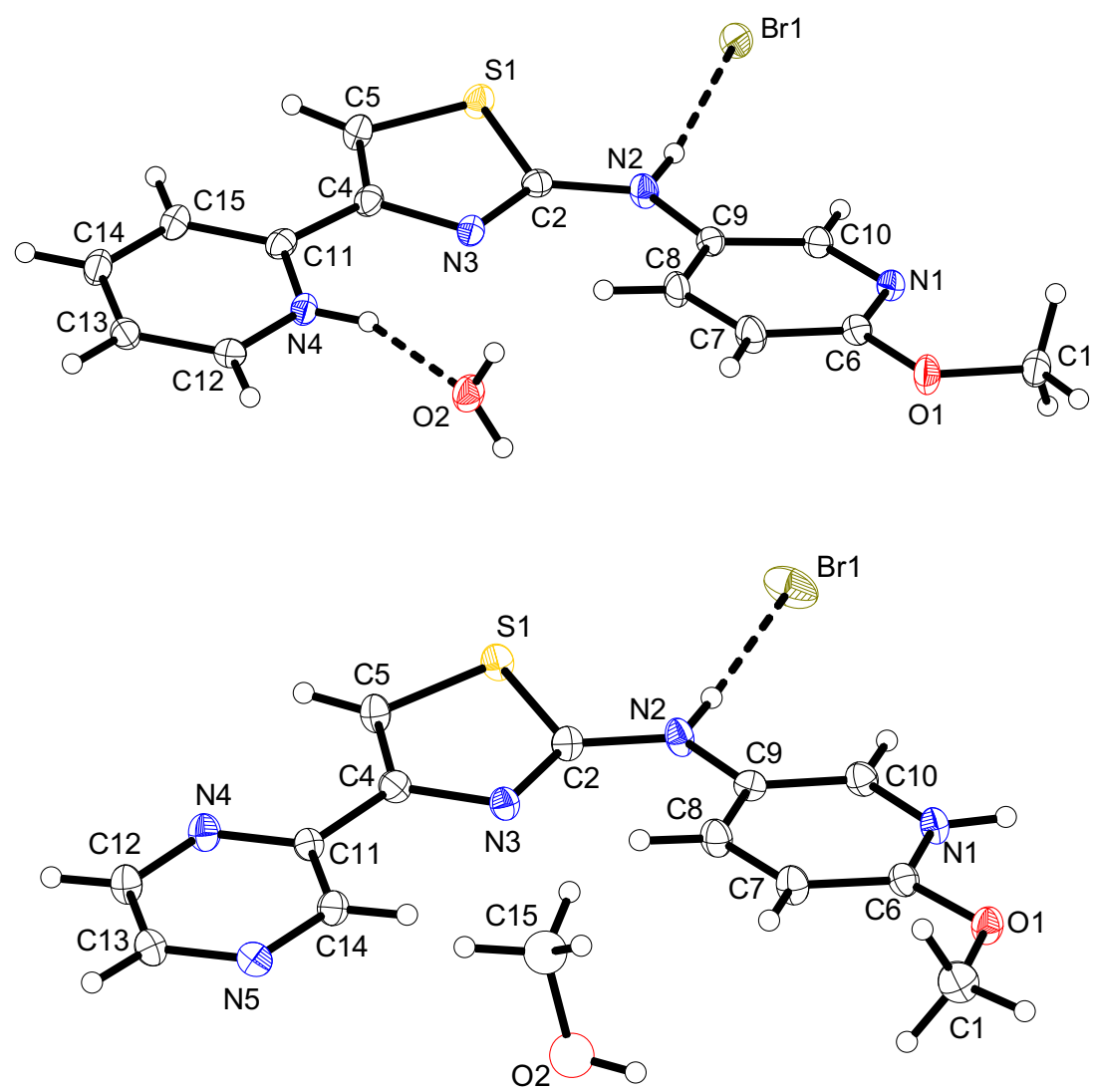

Optimization of the structures used the BFGS method from an initial Hessian according to Almoef's model with a very tight self-consistent field convergence threshold [27]. Calculations were made on the free cations of $\mathbf{3}$ and $\mathbf{4}$ as well as their corresponding free bases. Avogadro was used as a model editor and visualization tool [28]. The results of the DFT calculations are summarized in the Supplementary Material. The optimized structures exhibited no negative frequencies. Natural atomic charges were calculated using NBO analysis [29]. Structure overlay pictures were drawn with Mercury [30].

\section{Results and discussion}

The N,4-diheteroaryl 2-aminothiazole mono-hydrobromide salts investigated in this study were prepared using the Hantzsch thiazole synthesis [31, 32], as summarized in Scheme 1. Reactions of 2-bromo-1-(pyridine-2-yl)ethanone mono-hydrobromide and 2-bromo-1-(pyrazine-2-yl) ethanone mono-hydrobromide with $\mathbf{2}$ in ethanol afforded $\mathbf{3}$ and $\mathbf{4}$ after recrystallization from methanol. The compounds were structurally characterized by X-ray crystallography. Figure 1 depicts the molecular structures in the solid state.

In both 3 and $\mathbf{4}$, the structure of the central five-membered 1,3-thiazole heterocycle is as expected [33]. The $N$-(pyridin-3- yl)thiazol-2-amine unit adopts the same conformation in $\mathbf{3}$ and 4 with the sulfur atom and the pivot atom of the pyridine ring C9 in an antiperiplanar arrangement around the C2-N2 bond. A molecular conformation with a similar orientation of the two aryl rings was observed previously in some crystal structures of N,4-diaryl 2-aminothiazoles [34-36]. The thiazole and pyridine rings in $\mathbf{3}$ and $\mathbf{4}$ are not entirely coplanar. The angle between the respective mean planes is $10.43(7)^{\circ}$ in 3 and $12.6(1)^{\circ}$ in 4 . The mean planes of the heteroaryl rings

Table 2 Hydrogen bonds for $\mathbf{3}$ and $\mathbf{4}$

\begin{tabular}{lllll}
\hline$D-\mathrm{H} \cdots A$ & $d(D-\mathrm{H})$ & $d(\mathrm{H} \cdots A)$ & $d(D \cdots A)$ & $<(D \mathrm{HA})$ \\
\hline $\mathbf{3}^{\mathrm{a}}$ & & & & \\
$\mathrm{N} 2-\mathrm{H} 2 \cdots \mathrm{Br} 1$ & $0.863(17)$ & $2.467(18)$ & $3.3226(18)$ & $171(2)$ \\
$\mathrm{N} 4-\mathrm{H} 4 \cdots \mathrm{O} 2$ & $0.858(17)$ & $1.94(2)$ & $2.704(2)$ & $147(2)$ \\
$\mathrm{O} 2-\mathrm{H} 2 \mathrm{~A} \cdots \mathrm{Br} 1 \mathrm{a}$ & $0.830(17)$ & $2.483(18)$ & $3.3128(17)$ & $179(3)$ \\
$\mathrm{O} 2-\mathrm{H} 2 \mathrm{~B} \cdots \mathrm{Br} 1 \mathrm{~b}$ & $0.829(18)$ & $2.531(18)$ & $3.3539(17)$ & $173(3)$ \\
$\mathrm{C} 14-\mathrm{H} 14 \cdots \mathrm{N} 1 \mathrm{c}$ & 0.95 & 2.43 & $3.368(3)$ & 168 \\
$\mathbf{4}^{\mathrm{b}}$ & & & & \\
$\mathrm{N} 1-\mathrm{H} 1 \cdots \mathrm{N} 5 \mathrm{a}$ & $0.884(18)$ & $1.931(19)$ & $2.808(3)$ & $171(3)$ \\
$\mathrm{N} 2-\mathrm{H} 2 \cdots \mathrm{Br} 1$ & $0.874(18)$ & $2.355(18)$ & $3.228(2)$ & $177(3)$ \\
\hline
\end{tabular}

a Symmetry codes: (a) $x-1 / 2,-y+1 / 2, z-1 / 2$; (b) $-x+3 / 2, y+1 / 2,-z+$ $3 / 2$; (c) $x-3 / 2,-y+1 / 2, z-1 / 2$

${ }^{\mathrm{b}}$ Symmetry code: (a) $x+1 / 2,-y+1 / 2, z+1 / 2$ 
Table 3 Selected natural atomic charges (e) for calculated free cations and free bases of $\mathbf{3}$ and $\mathbf{4}$

\begin{tabular}{lllll}
\hline Atom number $^{\mathrm{a}}$ & $\mathbf{3}$ (cation) & $\mathbf{4}$ (cation) & $\mathbf{3}$ (free base) & $\mathbf{4}$ (free base) \\
\hline Positive & & & & \\
S1 & 0.43867 & 0.42585 & 0.34563 & 0.34574 \\
H1 & - & 0.44402 & - & - \\
H2 & 0.41178 & 0.41185 & 0.39616 & 0.39634 \\
H4 & 0.46263 & - & - & - \\
Negative & & & & \\
N1 & -0.47051 & -0.42745 & -0.47122 & -0.47341 \\
N2 & -0.55164 & -0.52947 & -0.54077 & -0.53978 \\
N3 & -0.53797 & -0.48917 & -0.49794 & -0.47084 \\
N4 & -0.42127 & -0.37532 & -0.41571 & -0.36370 \\
N5 & - & -0.36709 & - & -0.37629 \\
\hline
\end{tabular}

${ }^{a}$ Atom labelling scheme corresponding to the crystal structures

attached to $\mathrm{C} 4$ of the 1,3-thiazole ring are tilted out of its mean plane by only $1.88(6)^{\circ}$ in 3 and $6.8(1)^{\circ}$ in $\mathbf{4}$. Both monohydrobromide salts have in common a hydrogen bond formed by the secondary amino group to the bromide anion (Table 2). Moreover, the $\mathrm{S} 1 \cdots \mathrm{Br} 1$ short contacts of 3.5891(7) and $3.8344(8) \AA$ as well as the $\mathrm{C} 5-\mathrm{S} 1 \cdots \mathrm{Br}$ angles of $177.96(8)$ and $170.84(9)^{\circ}$ in $\mathbf{3}$ and $\mathbf{4}$, respectively, provide structural evidence for chalcogen bonding [37, 38]. This arrangement appears not to be unusual. A survey of the CSD (version 5.41 with August 2020 updates) revealed that of 24 crystal structures containing the 2-aminothiazole unit and a bromide anion, where coordinates were available, 17 structures exhibited a short $(<4.0 \AA) \mathrm{S} \cdots \mathrm{Br}$ distance and $\mathrm{C}-\mathrm{S} \cdots \mathrm{Br}$ angles in the range of $152-175^{\circ}$ (see Supplementary Material).

The protonation sites in both $\mathbf{3}$ and $\mathbf{4}$ were identified in difference electron density maps. The observed respective $\mathrm{C}-\mathrm{N}-\mathrm{C}$ bond angles in the six-membered heterocycles (Table S1 in the Supplementary Material) corroborate the assignments made. The C12-N4-C11 and C6-N1-C10 bond angles at the protonated N4 in $\mathbf{3}$ and N1 in 4, respectively, are significantly larger than $120^{\circ}$. In contrast, the $\mathrm{C}-\mathrm{N}-\mathrm{C}$ bond angles at the unprotonated pyridine and pyrazine nitrogen atoms are within $116-117^{\circ}$ and thus significantly smaller than $120^{\circ}$. In 3 , the pyridine ring attached to $\mathrm{C} 4$ of the $1,3-$ thiazole ring is protonated, whereas the 2-methoxypyridine ring bonded to the amino group remains unprotonated. Since pyrazine is a weaker base than pyridine, protonation of the 2methoxypyridine ring is preferred to protonation of the pyrazine ring in $\mathbf{4}$ as expected.

It is worth noting that in the crystal structure of $\mathbf{3}$, the bromide anion is involved in a hydrogen bond with $\mathrm{H} 2$ at the amine nitrogen atom; although $\mathrm{H} 4$ attached to the pyridinium nitrogen atom, the site of protonation of the free base exhibits the larger natural charge in the cation calculated by DFT methods and subsequent NBO analysis (Table 3 ). Similarly, in the crystal structure of $\mathbf{4}$, the bromide anion is involved in a hydrogen bond with $\mathrm{H} 2$; although $\mathrm{H} 1$ attached to the methoxypyridinium nitrogen atom, here the site of protonation has the larger natural charge in the calculated cation. Natural atomic charge or the site of protonation of the free base does therefore not appear to be an indicator of why the bromide anion is hydrogen-bonded to the amine $\mathrm{H}$ atom. In the crystal structures of both 3 and $\mathbf{4}$, the $\mathrm{N}_{\text {amine }}-\mathrm{H} \cdots \mathrm{Br}$ angles
Fig. 2 Structure overlays of the thiazole units of the DFToptimized structures of the cations (green) and free bases (orange) of 3 (top) and 4 (bottom). Sulfur and nitrogen atoms are highlighted with yellow and blue, respectively
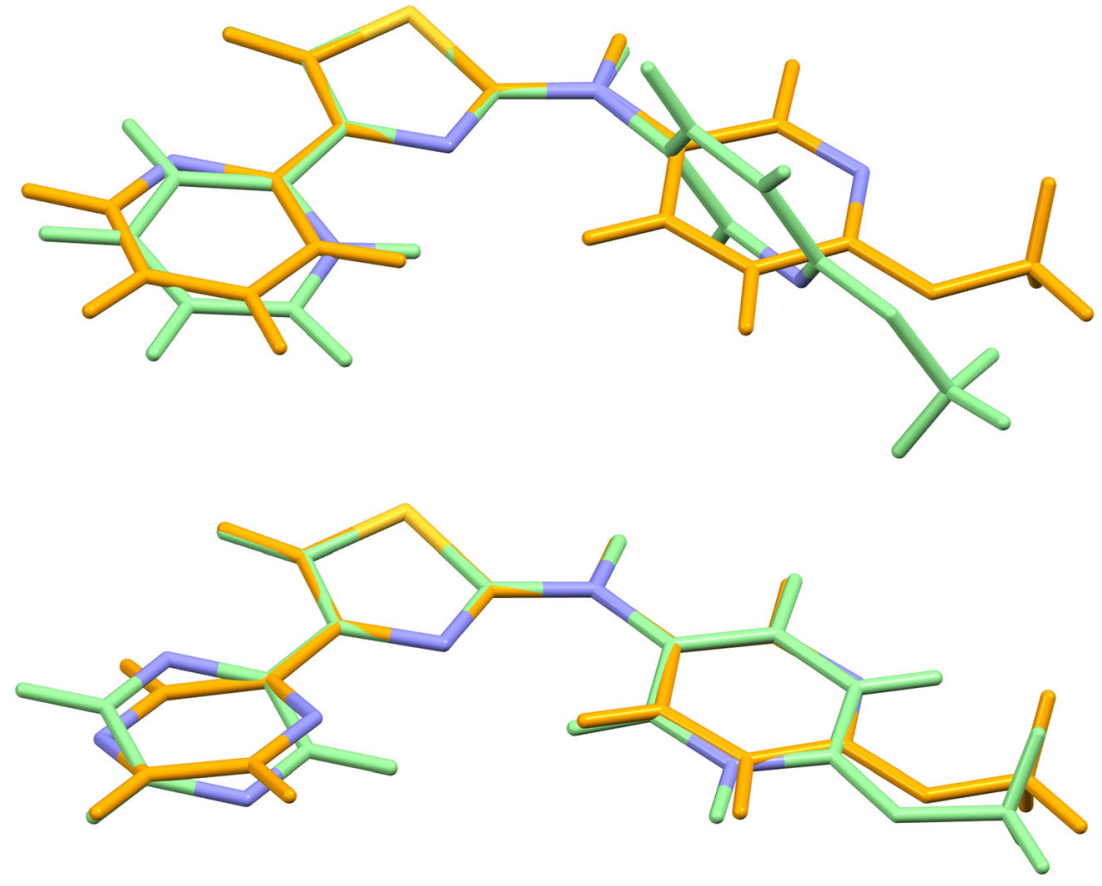
Fig. 3 Part of the crystal structure of 3. $\mathrm{N}_{\text {amine }}-\mathrm{H}^{\cdots} \mathrm{Br}^{-}, \mathrm{N}^{+}$pyridine ${ }^{-}$ $\mathrm{H}^{\cdots} \mathrm{O}_{\text {water }}$ and $\mathrm{O}_{\text {water }}-\mathrm{H}^{\cdots} \cdot \mathrm{Br}$ hydrogen bonds (dashed lines), viewed down the $a$ axis direction. Carbon-bound hydrogen atoms are omitted for clarity. Symmetry codes: (a) $x-1 / 2,-y+1 / 2, z-1$ / 2 ; (b) $-x+3 / 2, y+1 / 2,-z+3 / 2$

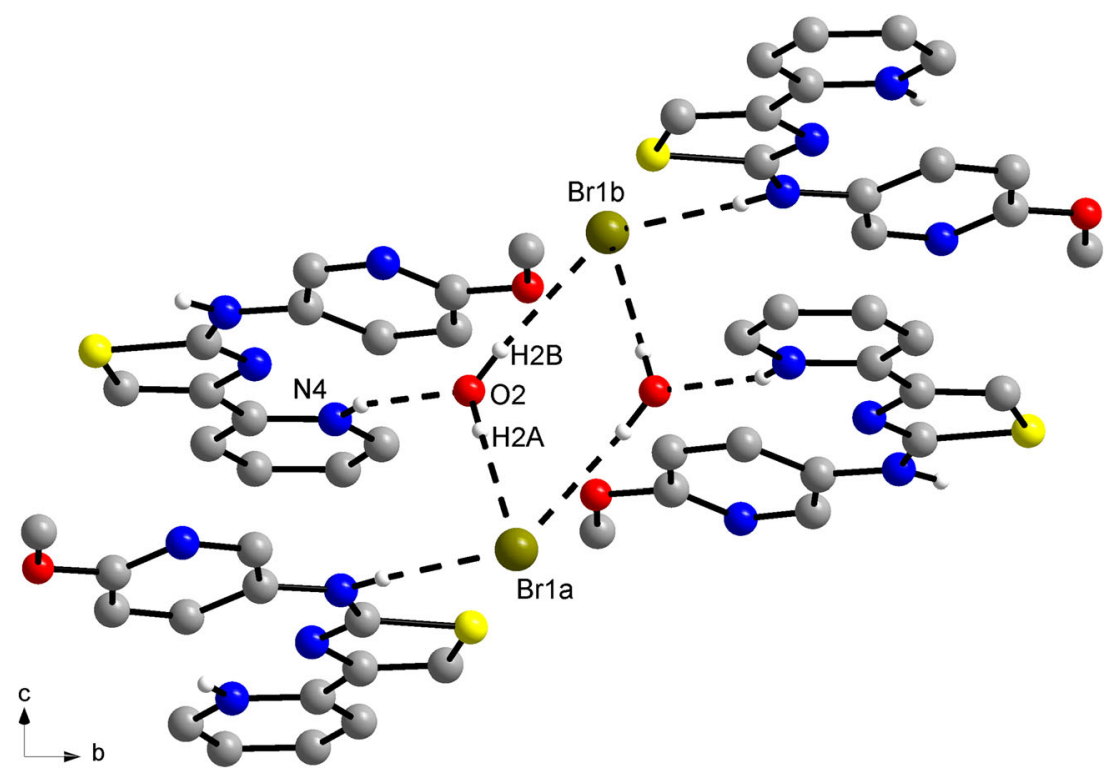

are close to $180^{\circ}$ (Table 2), indicating that the main interaction is with the amine $\mathrm{H}$ atom, although it is worth noting that the second highest positively charged atom in both cases is the sulfur atom ( 3 cation $0.43867 \mathrm{e}$ and $\mathbf{4}$ cation $0.42585 \mathrm{e}$ ). In contrast, the amine nitrogen atom is the atom with the most negative natural atomic charge of all atoms in the calculated free cations of $3(-0.55164 \mathrm{e})$ and $4(-0.52947 \mathrm{e})$. For the calculated free bases, the largest positive natural atomic charge resides on the amine $\mathrm{H}$ atom ( 3 free base $0.39616 \mathrm{e}$ and 4 free base 0.39634 e) closely followed by the sulfur atom (3 free base $0.34563 \mathrm{e}, 4$ free base $0.34574 \mathrm{e}$ ), whereas the atom with the most negative natural atomic charge is the amine nitrogen atom in both cases ( 3 free base $-0.54077 \mathrm{e}$, 4 free base $-0.53978 \mathrm{e}$ ), as for the calculated cations.

In $\mathbf{4}$, the methoxy group in ortho-position to N1 is rotated by approximately $180^{\circ}$ compared with $\mathbf{3}$, which appears to be associated with the protonation state of N1. This observation is mirrored in the DFT-optimized structures of the free cations and free bases of $\mathbf{3}$ and $\mathbf{4}$ (Fig. 2), whereby the methoxy group in the ortho-position to N1 only points away from N1 when it is protonated (cation of 4).

As shown in Fig. 3, $\mathrm{N}_{\text {amine }}-\mathrm{H}^{\cdots} \mathrm{Br}^{-}, \mathrm{N}_{\text {pyridine }}^{+}-\mathrm{H}^{\cdots} \mathrm{O}_{\text {water }}$, and $\mathrm{O}_{\text {water }}-\mathrm{H}^{\cdots} \mathrm{Br}^{-}$hydrogen bonds dominate the supramolecular structure of $\mathbf{3}$ in the solid state. Two solvate water molecules and two bromide anions form a centrosymmetric $\mathrm{R}_{4}^{2}(8)$ hydrogen bond motif [39], which is surrounded by protonated $\mathrm{N}$-(6-methoxypyridin-3-yl)-4-(pyridin-2yl)thiazol-2-amine molecules. The protonated pyridin-2-yl group forms a hydrogen bond to the solvate water molecule and, as mentioned above, the amino group to a bromide anion, affording a three-dimensional hydrogen-bonded structure. In addition, the unprotonated pyridine nitrogen atom $\mathrm{N} 1$ appears to accept a weak $\mathrm{C}-\mathrm{H} \cdots \mathrm{N}$ hydrogen bond from $\mathrm{C} 14$ of an adjacent molecule (Figure S1 in the Supplementary

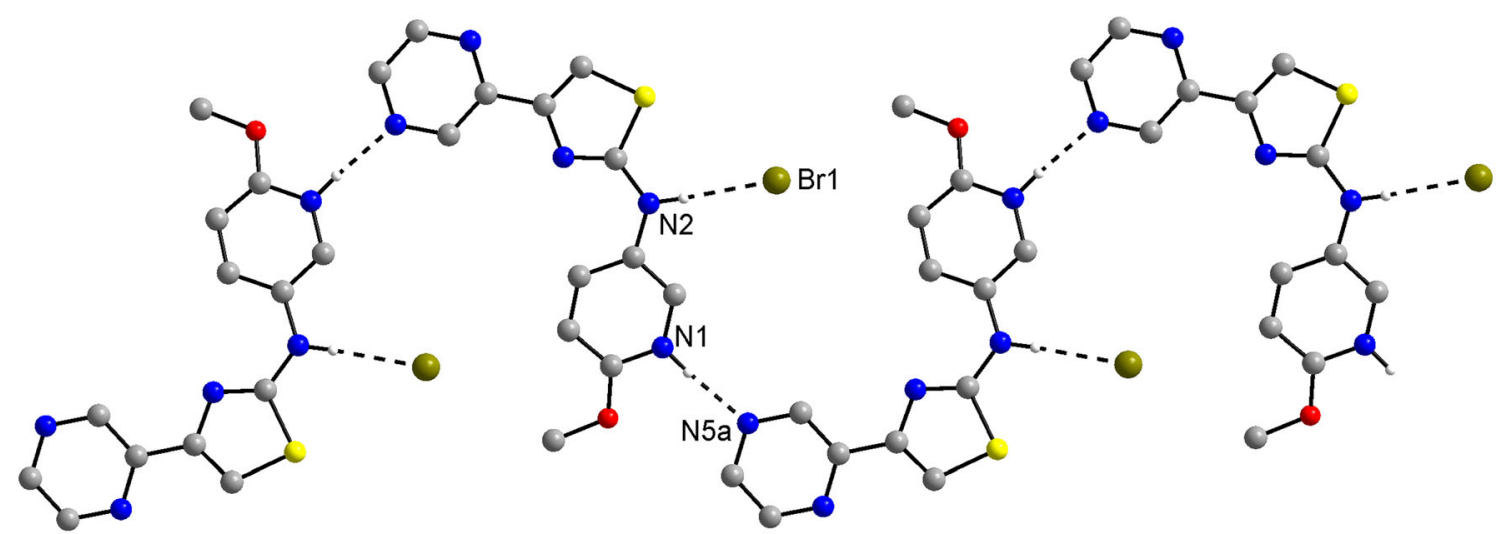

Fig. $4 \mathrm{~N}^{+}$methoxypyridine $-\mathrm{H}^{\cdots} \mathrm{N}_{\text {pyrazine }}$ hydrogen-bonded zigzag chain in the crystal structure of 4 , viewed towards the (-101) plane. Carbon-bound hydrogen atoms and disordered methanol solvent molecules of crystallization are omitted for clarity. Symmetry code: (a) $x+1 / 2,-y+1 / 2, z+1 / 2$ 
Material). The centroid-centroid distance between face-toface stacked methoxypyridine rings and thiazole rings is $3.51 \AA$. The hydrogen bonding scheme in $\mathbf{4}$ is distinctly different from that in 3. In 4, protonated $N$-(6-methoxypyridin-3yl)-4-(pyrazin-2-yl)thiazol-2-amine molecules are joined via $\mathrm{N}^{+}-\mathrm{H} \cdots \mathrm{N}$ hydrogen bonds between the protonated methoxypyridine ring and the pyrazine nitrogen atom N5 of an adjacent molecule, resulting in zigzag chains extending in the [101] direction in the crystal (Fig. 4). The second pyrazine nitrogen atom remains without a hydrogen bond donor in the crystal structure. The disordered solvate methanol molecule is also not involved in significant hydrogen bonding interactions. Geometric parameters of hydrogen bonds in $\mathbf{3}$ and $\mathbf{4}$, as summarized in Table 2, are within expected ranges [40].

\section{Conclusions}

We have prepared the two related $N$,4-diheteroaryl 2aminothiazoles $\mathbf{3}$ and $\mathbf{4}$ using the Hantzsch thiazole synthesis and structurally characterized their mono-hydrobromide salts. The N,4-diheteroaryl 2-aminothiazole cations exhibit similar molecular conformations in the solid state but different sites of protonation. The intermolecular hydrogen bonding patterns in the crystal structures are markedly different. Despite the different solid-state supramolecular structures, a similar $\mathrm{N}_{\text {amine }}{ }^{-}$ $\mathrm{H} \cdots \mathrm{Br}^{-} \cdots \mathrm{S}$ association is encountered in both $\mathbf{3}$ and $\mathbf{4}$, indicating a preferred interaction of these groups, even though the site of protonation of the free base is elsewhere. With regard to the hitherto limited knowledge of $N, 4$-diheteroaryl 2-aminothiazole mono-hydrobromide salts, structural information gained from the present study should be conducive for further investigations of this compound class in medicinal chemistry.

Supplementary Information The online version contains supplementary material available at https://doi.org/10.1007/s11224-021-01730-0.

Acknowledgments Professor Christian W. Lehmann is gratefully acknowledged for providing access to the X-ray diffraction facility. RWS would like to thank Jan Henrik Halz for helpful discussions.

Code availability Not applicable.

Authors' contributions Conceptualization: PI and RWS; data curation: RWS, RG, and AR; formal analysis: RWS, RG, and AR; investigation: $\mathrm{DB}, \mathrm{AB}$, and RG; methodology: RG and RWS; project administration: PI and RWS; supervision: PI; validation: RWS, RG, and AR; visualization: RWS and RG; writing - original draft: RWS and RG; writing, review, and editing: RWS, RG, and PI.

Funding Open Access funding enabled and organized by Projekt DEAL.

Data availability Results of the DFT calculations have been placed in the electronic Supplementary Material. CCDC 2043373 (3) and 2043374 (4) contain the supplementary crystallographic data for this paper. These data can be obtained free of charge from the Cambridge Crystallographic Data Centre via www.ccdc.cam.ac.uk/structures.

\section{Compliance with ethical standards}

Conflict of interest The authors declare that they have no conflicts of interest.

Ethics approval Not applicable.

Consent to participate Not applicable.

Consent for publication All co-authors have seen and approved the manuscript.

Open Access This article is licensed under a Creative Commons Attribution 4.0 International License, which permits use, sharing, adaptation, distribution and reproduction in any medium or format, as long as you give appropriate credit to the original author(s) and the source, provide a link to the Creative Commons licence, and indicate if changes were made. The images or other third party material in this article are included in the article's Creative Commons licence, unless indicated otherwise in a credit line to the material. If material is not included in the article's Creative Commons licence and your intended use is not permitted by statutory regulation or exceeds the permitted use, you will need to obtain permission directly from the copyright holder. To view a copy of this licence, visit http://creativecommons.org/licenses/by/4.0/.

\section{References}

1. Das D, Sikdar P, Bairagi M (2016) Recent developments of 2aminothiazoles in medicinal chemistry. Eur J Med Chem 109:8998. https://doi.org/10.1016/j.ejmech.2015.12.022

2. Bhuniya D, Mukkavilli R, Shivahare R, Launay D, Dere RT, Deshpande A, Verma A, Vishwakarma P, Moger M, Pradhan A, Pati H, Gopinath VS, Gupta S, Puri SK, Martin D (2015) Aminothiazoles: hit to lead development to identify antileishmanial agents. Eur J Med Chem 102:582-593. https://doi.org/10.1016/j. ejmech.2015.08.013

3. Paquet T, Gordon R, Waterson D, Witty MJ, Chibale K (2012) Antimalarial aminothiazoles and aminopyridines from phenotypic whole-cell screening of a SoftFocus ${ }^{\circledR}$ library. Future Med Chem 4(18):2265-2277. https://doi.org/10.4155/fmc.12.176

4. Kesicki EA, Bailey MA, Ovechkina Y, Early JV, Alling T, Bowman J, Zuniga ES, Dalai S, Kumar N, Masquelin T, Hipskind PA, Odingo JO, Parish T (2016) Synthesis and evaluation of the 2-aminothiazoles as anti-tubercular agents. PLoS One 11(5): e0155209. https://doi.org/10.1371/journal.pone.0155209

5. Meissner A, Boshoff HI, Vasan M, Duckworth BP, Barry 3rd CE, Aldrich CC (2013) Structure-activity relationships of 2aminothiazoles effective against Mycobacterium tuberculosis. Bioorg Med Chem 21(21):6385-6397. https://doi.org/10.1016/j. bmc.2013.08.048

6. Makam P, Kannan T (2014) 2-Aminothiazole derivatives as antimycobacterial agents: synthesis, characterization, in vitro and in silico studies. Eur J Med Chem 87:643-656. https://doi.org/10. 1016/j.ejmech.2014.09.086

7. Beuchel A, Goddard R, Imming P, Seidel RW (2020) A solid solution of ethyl and d3-methyl 2-[(4-methylpyridin-2-yl)amino]-4(pyridin-2-yl)thiazole-5-carboxylate. Acta Crystallogr E 
Crystallogr Commun 76(8):1255-1259. https://doi.org/10.1107/ S2056989020008956

8. Böck D, Beuchel A, Goddard R, Imming P, Seidel RW (2020) Structural characterization of two polymorphs of 1-(4methylpyridin-2-yl)thiourea and two derived 2-aminothiazoles. J Chem Crystallogr. https://doi.org/10.1007/s10870-020-00863-0

9. Gupta D, Bhatia D, Dave V, Sutariya V, Varghese Gupta S (2018) Salts of therapeutic agents: chemical, physicochemical, and biological considerations. Molecules 23(7). https://doi.org/10.3390/ molecules23071719

10. Groom CR, Bruno IJ, Lightfoot MP, Ward SC (2016) The Cambridge Structural Database. Acta Crystallogr Sect B: Struct Sci Cryst Eng Mater 72(Pt 2):171-179. https://doi.org/10.1107/ S2052520616003954

11. Thomas IR, Bruno IJ, Cole JC, Macrae CF, Pidcock E, Wood PA (2010) WebCSD: the online portal to the Cambridge Structural Database. J Appl Crystallogr 43:362-366. https://doi.org/10.1107/ s0021889810000452

12. Hassan AA, Mohamed NK, Aly AA, Tawfeek HN, Bräse S, Nieger M (2020) Synthesis and structure confirmation of 2,4-disubstituted thiazole and 2,3,4-trisubstituted thiazole as thiazolium bromide salts. Monatsh Chem 151(7):1143-1152. https://doi.org/10.1007/ s00706-020-02640-3

13. Cuconati A, Xu X, Block TM (2013) Preparation of substituted aminothiazoles as inhibitors of cancers, including hepatocellular carcinoma, and as inhibitors of hepatitis virus replication. WO2013052613A1,

14. Kretschmer MSB, Woltersdorf S, Rödl CB, Vogt D, Häfner A-K, Steinhilber D, Stark H, Hofmann B (2016) Development of novel aminothiazole-comprising 5-LO inhibitors. Future Med Chem 8(2): 149-164. https://doi.org/10.4155/fmc.15.174

15. Sarkis GY, Faisal ED (1985) Synthesis and spectroscopic properties of some new N,N'-disubstituted thiorueas of potential biological interest. J Heterocyclic Chem 22(1):137-140. https://doi.org/10. 1002/jhet.5570220134

16. Dicks JP, Zubair M, Davies ES, Garner CD, Schulzke C, Wilson C, McMaster J (2015) Synthesis, structure and redox properties of asymmetric (cyclopentadienyl)(ene-1,2-dithiolate)cobalt(III) complexes containing phenyl, pyridyl and pyrazinyl units. Eur J Inorg Chem 2015(21):3550-3561. https://doi.org/10.1002/ejic. 201500138

17. SAINT (2012) Bruker AXS Inc. Madison, Wisconsin, USA

18. Duisenberg AJM, Kroon-Batenburg LMJ, Schreurs AMM (2003) An intensity evaluation method: EVAL-14. J Appl Crystallogr 36(2):220-229. https://doi.org/10.1107/S0021889802022628

19. SADABS (2012) Bruker AXS Inc. Madison, Wisconsin

20. Sheldrick GM (2015) SHELXT - integrated space-group and crystal-structure determination. Acta Crystallogr A Found Adv 71(Pt 1):3-8. https://doi.org/10.1107/S2053273314026370

21. Sheldrick GM (2015) Crystal structure refinement with SHELXL. Acta Crystallogr C Struct Chem 71(Pt 1):3-8. https://doi.org/10. $1107 / \mathrm{S} 2053229614024218$

22. Brandenburg K (2018) Diamond. 3.2k3 edn. Crystal Impact GbR, Bonn

23. Neese F (2018) Software update: the ORCA program system, version 4.0. WIREs Comput Mol Sci 8(1):e1327. https://doi.org/10. 1002/wcms. 1327

24. Becke AD (1993) Density-functional thermochemistry. III. The role of exact exchange. J Chem Phys 98(7):5648-5652. https:// doi.org/10.1063/1.464913

25. Lee C, Yang W, Parr RG (1988) Development of the Colle-Salvetti correlation-energy formula into a functional of the electron density.
Phys Rev B 37(2):785-789. https://doi.org/10.1103/PhysRevB.37. 785

26. Weigend F, Ahlrichs R (2005) Balanced basis sets of split valence, triple zeta valence and quadruple zeta valence quality for $\mathrm{H}$ to $\mathrm{Rn}$ : design and assessment of accuracy. Phys Chem Chem Phys 7(18): 3297-3305. https://doi.org/10.1039/B508541A

27. Fletcher R (2000) Practical methods of optimization, 2nd edn. John Wiley \& Sons, Chichester

28. Hanwell MD, Curtis DE, Lonie DC, Vandermeersch T, Zurek E, Hutchison GR (2012) Avogadro: an advanced semantic chemical editor, visualization, and analysis platform. J Cheminformat 4(1): 17. https://doi.org/10.1186/1758-2946-4-17

29. Glendening JED, Badenhoop K, Reed AE, Carpenter JE, Bohmann JA, Morales CM, Karafiloglou P, Landis CR, Weinhold F (2018) NBO 7.0. Theoretical Chemistry Institute, University of Wisconsin, Madison

30. Macrae CF, Sovago I, Cottrell SJ, Galek PTA, McCabe P, Pidcock E, Platings M, Shields GP, Stevens JS, Towler M, Wood PA (2020) Mercury 4.0: from visualization to analysis, design and prediction. $\mathrm{J}$ Appl Crystallogr 53(Pt 1):226-235. https://doi.org/10.1107/ S1600576719014092

31. Hantzsch A, Weber JH (1887) Ueber Verbindungen des Thiazols (Pyridins der Thiophenreihe). Ber Dtsch Chem Ges 20(2):3118 3132. https://doi.org/10.1002/cber.188702002200

32. Wang $Z$ (2010) Hantzsch thiazole synthesis. In: Comprehensive organic name reactions and reagents. pp. 1330-1334. https://doi. org/10.1002/9780470638859.conrr296

33. Eicher TH, Siegfried, Speicher A (2013) The chemistry of heterocycles: structures, reactions, synthesis, and applications, 3rd, completely revised and enlarged edition. Wiley-VCH, Weinheim

34. Kuleshova LN, Averkiev BB, Gusev DV, Suponitskii KY, Antipin MY (2004) Conformational polymorphism of N-(4-butoxyphenyl)4-(4'-nitrophenyl)-2-thiazolamine. Crystallogr Rep 49(5):798-806. https://doi.org/10.1134/1.1803309

35. He L-M, Hu A-X, Cao G, Peng J-J (2007) Ethyl 2-methyl-1-(4phenylthiazol-2-yl)-1H-benzimidazole-6-carboxylate. Acta Crystallogr E Crystallogr Commun 63(8):03643. https://doi.org/ $10.1107 / \mathrm{S} 1600536807036483$

36. Shao L, Zhou X, Fang J-X (2006) 4-(4-Chlorophenyl)-N-phenyl-5(1H-1,2,4-triazol-1-yl)thiazol-2-amine. Acta Crystallogr E Crystallogr Commun 62(1):091-093. https://doi.org/10.1107/ S1600536805040146

37. Scilabra P, Terraneo G, Resnati G (2019) The chalcogen bond in crystalline solids: a world parallel to halogen bond. Acc Chem Res 52(5):1313-1324. https://doi.org/10.1021/acs.accounts.9b00037

38. Vogel L, Wonner P, Huber SM (2019) Chalcogen bonding: an overview. Angew Chem Int Ed 58(7):1880-1891. https://doi.org/ 10.1002/anie.201809432

39. Bernstein J, Davis RE, Shimoni L, Chang NL (1995) Patterns in hydrogen bonding - functionality and graph set analysis in crystals. Angew Chem Int Edit 34(15):1555-1573. https://doi.org/10.1002/ anie. 199515551

40. Thakuria R, Sarma B, Nangia A (2017) 7.03 - Hydrogen bonding in molecular crystals. In: Atwood JL (ed) Comprehensive supramolecular chemistry II. Elsevier, Oxford, pp 25-48. https://doi.org/10. 1016/B978-0-12-409547-2.12598-3

Publisher's note Springer Nature remains neutral with regard to jurisdictional claims in published maps and institutional affiliations. 